\title{
Publisher Correction: The immune cell landscape in kidneys of patients with lupus nephritis
}

Arnon Arazi, Deepak A. Rao, Celine C. Berthier, Anne Davidson, Yanyan Liu, Paul J. Hoover, Adam Chicoine, Thomas M. Eisenhaure (D), A. Helena Jonsson, Shuqiang Li, David J. Lieb (D), Fan Zhang, Kamil Slowikowski,

Edward P. Browne, Akiko Noma, Danielle Sutherby, Scott Steelman, Dawn E. Smilek, Patti Tosta, William Apruzzese, Elena Massarotti, Maria Dall'Era, Meyeon Park, Diane L. Kamen, Richard A. Furie, Fernanda Payan-Schober, William F. Pendergraft III, Elizabeth A. McInnis, Jill P. Buyon (D), Michelle A. Petri, Chaim Putterman (D),

Kenneth C. Kalunian, E. Steve Woodle, James A. Lederer, David A. Hildeman (D, Chad Nusbaum, Soumya Raychaudhuri, Matthias Kretzler (D), Jennifer H. Anolik, Michael B. Brenner (D), David Wofsy, Nir Hacohen (D), Betty Diamond (D) and the Accelerating Medicines Partnership in SLE network

Correction to: Nature Immunology https://doi.org/10.1038/s41590-019-0398-x, published online 17 June 2019.

In the version of this article initially published, the bottom plot in Fig. 5b was aligned incorrectly with the plots above, and the following authors (and their affiliations) were missing from the complete list of authors at the end of the text: H. Michael Belmont (Department of Medicine, Division of Rheumatology, New York University School of Medicine, New York, NY, USA), Peter M. Izmirly (Department of Medicine, Division of Rheumatology, New York University School of Medicine, New York, NY, USA), Pavel Morozov (Laboratory for RNA Molecular Biology, The Rockefeller University, New York, New York, USA) and Manjunath Kustagi (Laboratory for RNA Molecular Biology, The Rockefeller University, New York, New York, USA). The correct list should end as follows: Andrea Fava ${ }^{18}$, H. Michael Belmont ${ }^{17}$, Peter M. Izmirly ${ }^{17}$, Pavel Morozov ${ }^{34}$, Manjunath Kustagi ${ }^{34}$ and Daniel H. Goldman ${ }^{18}$." The errors have been corrected in the HTML and PDF versions of the article.
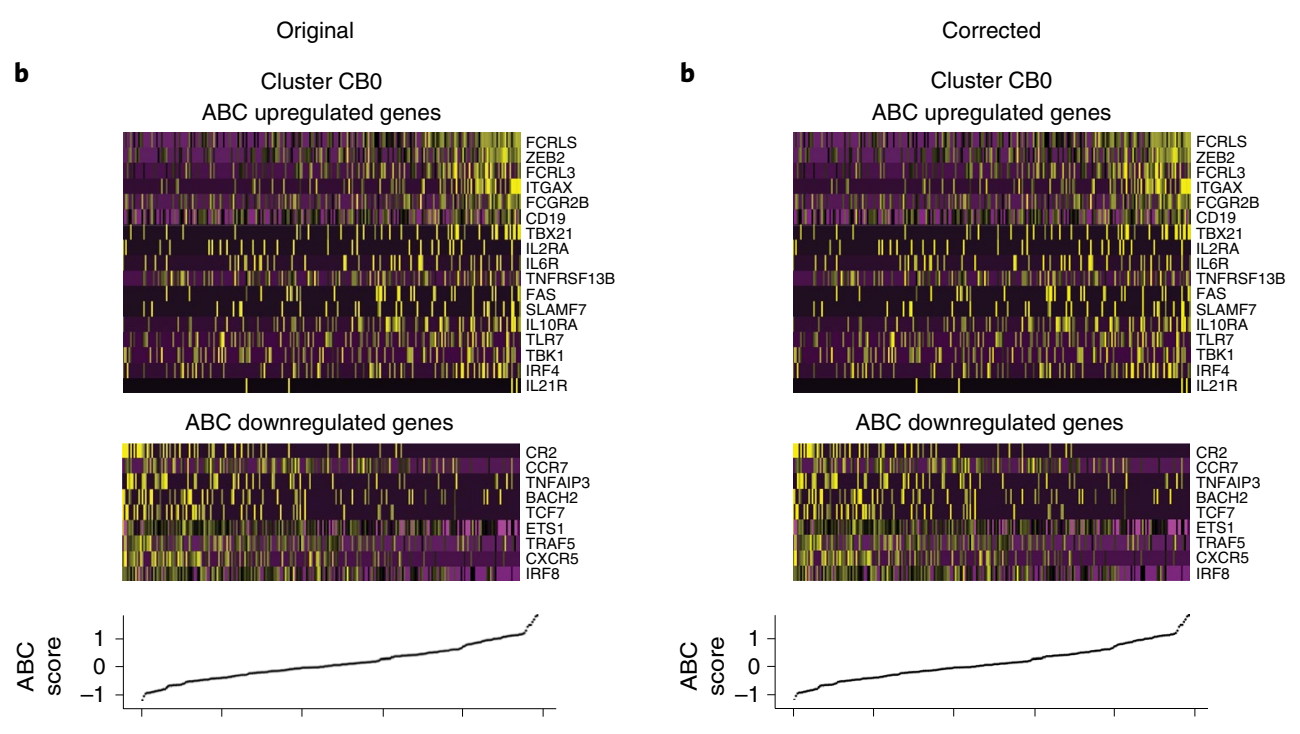

Fig. 5 | Original and Corrected. 